\title{
Matrix-assisted Laser Desorption of Peptides in Transmission Geometry
}

\author{
Akos Vertes* Laszlo Balazs and Renaat Gijbels \\ Department of Chemistry, University of Antwerp (UIA). Universiteitsplein 1. B-2610 Wilrijk. Belgium
}

SPONSOR REFEREE: Yvon Le Beyec, Institut de Physique Nucleaire. BP1. 9141k Orsay, France

\begin{abstract}
The possibility of performing matrix-assisted laser desorption experiments in tránsmission geometry is demonstrated for two neuropeptides (substance $P$ and bombesin), for six analogs of the melanocyte-stimulating hormone (MSH) core and for collagenase enzyme substrates. Positive- and negative-ion spectra of several peptides are produced without the presence of a metallic substrate. Cationized quasi-molecular ions are abundant in the positive spectra. Peak broadening in the high-mass range can be the consequence of overlapping molecular and adduct ions. The presence of synthesis by-products can be identified readily from the spectra. Ultimately, picogram detection limits are possible for important bioactive peptides and other large molecules. Because of the clearly demonstrated matrix-assisted laser ionization in a homogeneous environment, metal substrate participation in the volatilization mechanism seems less likely.
\end{abstract}

The recent upsurge of laser-desorption studies originated in the discovery of the matrix-assisted method.' It has carved out a distinguished place in the schedule of several current conferences. ${ }^{-t}$ Laser desorption seems to compete quite successfully with plasma desorption ${ }^{5}$ and with electrospray ionization ${ }^{h}$ for being the ultimate method of volatilizing and ionizing highmolecular-mass substances. In fact. the matrix-assisted UV laser desorption method has been demonstrated to produce molecular ions of proteins of mol.wt $\leqslant$ $3000\left(00 .^{7}\right.$ Other compound groups of biological significance viz., oligonucleotides and carbohydrates ${ }^{\star}$ show similar favorable spectral responses with the matrixassisted method.

The procedure of sample preparation and spectrum collection is attractively simple. A dilute (about $10^{-4}-10^{-5} \mathrm{~mol} / \mathrm{L}$ ) solution of the analyte is mixed with a more concentrated solution of the matrix and applied and dried onto a metallic sample holder. The concentration of the solid-analyte/matrix system is about $0.001-0.00(0) 1$ molar ratio with matrix excess. The matrix first used was nicotinic acid' but other matrices. for example cinnamic acid derivatives, proved to be useful as well."

Different lasers were utilized with wavelengths ranging from $266 \mathrm{~nm}$ to $355 \mathrm{~nm}$." Time-of-flight mass analyzers with or without ion reflector provided a mass range broad enough to deal with high molecular weight biological molecules and enough transmission to detect these molecules in extremely small amounts (i.e., in the femtomole range). lons were post-accelerated to about $20 \mathrm{keV}$ to improve the sensitivity of the electron multiplier or multichannel plate detectors in the high mass region.

The question addressed in this Communication concerns the geometry of laser illumination and the role of the metallic substrate in the volatilization/ionization mechanism. In all past experiments the so called reflection geometry was used, i.e., the laser illumination and the mass analyzer were on the same side of the sample. It was not clear on the basis of previous work in the

\footnotetext{
- Author to whom correspondence should he addressed.
}

field whether or not it is possible to investigate thin or small samples in transmission geometry, i.e., in a setup where laser illumination and mass analyzer are on opposite sides of the sample. Another notable difference between these two geometries is the presence or absence of a metallic substrate. In the generally used reflection geometry, the sample solution is dried onto a metallic sample holder and forms a thin surface layer. In the transmission geometry the sample solution is dried onto an extremely thin plastic film covering an electron-microscope grid. Therefore, no metallic substrate is present in the vicinity of illumination and ion formation. Thus, we also expect some information from the experiments about substrate participation in the desorption and ionization processes.

\section{EXPERIMENTAL}

The instrument was a standard LAMMA 500-type (Leybold Heraeus, San José, CA, USA) time-of-flight mass spectrometer equipped with a frequencyquadrupled Nd-YAG laser arranged in transmission geometry. The mass spectrometer and laser settings were within the limits of normal operating conditions. Laser pulses were attenuated to the threshold levels where sample-specific ions started to appear. The positive- and negative-ion modes were both utilized in the case of all the peptides. Single-shot spectra were collected in every case; however, averaging of spectra was also used. Mass calibration was carried out using characteristic peaks of the nicotinic acid matrix. This method provided internal reference peaks up to about 3() $u$. At higher masses the scale was determined by extrapolation, giving rise to surprisingly good accuracy even in the region of $1600 \mathrm{u}$. In çertain cases confirmation of the extrapolated values was possible by comparing the positive and negative spectra. If the quasimolecular peaks appeared at a mass difference of $2 u$ in the two spectra the identification of the $[\mathrm{M}+\mathrm{H}]^{+}$and $[\mathrm{M}-\mathrm{H}]^{-}$ions was more certain.

Ten different peptides were investigated having molecular weights in the $740-1620$ Da range (see Table 


\begin{tabular}{|c|c|c|c|c|c|}
\hline \multirow[b]{2}{*}{ Simplc } & \multirow[b]{2}{*}{ Samiple name } & \multicolumn{2}{|c|}{ Ponvitici prictrat } & \multirow{2}{*}{\multicolumn{2}{|c|}{ High int peiahs Nepattre ypectrat }} \\
\hline & & Hogh Im peith & l.ou int peiaks & & \\
\hline $\mathbf{1}$ & Suhstance-P & $1348:|M+H|$ & & & \\
\hline 2 & Bombesin & $1619:|M+H|$ & & & \\
\hline 3 & $\begin{array}{l}\text { c|Gly-His(D)Phe-Arg }\left(\mathrm{NO}_{2}\right)- \\
\text { Trp-Gly| }\end{array}$ & $\begin{array}{l}741: \mid \mathrm{M}-\mathrm{NO})_{2}+\mathrm{H} \mid \\
8(1,3:|\mathrm{M}+17|\end{array}$ & $\begin{array}{l}769:\left|M-N O_{2}+\mathrm{H}+28\right| \\
786: \mathrm{M} \\
819:|\mathrm{M}+33|^{\circ}\end{array}$ & & 7.39: [M-NO, $-\mathrm{H}]$ \\
\hline 4 & $\begin{array}{l}\text { [H-Gly-His-(D)Phe-Arg-Trp- } \\
\text { Gly-OCH:] }\end{array}$ & 77.3: $\mathrm{M}$ & $\begin{array}{l}759:[\mathrm{M}-14]^{\circ} \\
789:[\mathrm{M}+16] \\
801:[\mathrm{M}+28]^{\circ}\end{array}$ & $\cdot ?$ & $\begin{array}{l}758: \mid M-15] \\
772:|M-H|\end{array}$ \\
\hline 5 & $\begin{array}{l}\text { c|Gly-His-Phe-Arg(NO_)- } \\
\text { Trp-Gly| }\end{array}$ & $7+1:\left|\mathrm{M}-\mathrm{NO}_{2}+\mathrm{H}\right|^{\circ}$ & $\begin{array}{l}769:\left[\mathrm{M}-\mathrm{NO}_{2}+\mathrm{H}+28\right]^{\circ} \\
786: \mathrm{M} \\
818:[\mathrm{M}+32]\end{array}$ & & $\begin{array}{l}\text { 739: }\left[\mathrm{M}-\mathrm{NO}_{2}-\mathrm{H}\right] \\
\text { 756: }\left[\mathrm{M}-\mathrm{NO} \mathrm{O}_{2}+17\right] \\
\text { 785: }[\mathrm{M}-\mathrm{H}]\end{array}$ \\
\hline 6 & $\begin{array}{l}\text { c|Gly-His-Phe-Arg-Trp- } \\
\text { Gly].HOAc }\end{array}$ & $\begin{array}{l}\text { 741: } M \\
\text { 742: }|M+H| \\
803:|M+62|\end{array}$ & & & \\
\hline 7 & $\begin{array}{l}\text { c|Gly-His-(D)Phe-Arg-Trp- } \\
\text { Gly|.HOAc }\end{array}$ & $\begin{array}{l}7+1: M \\
8(13:[M+62]\end{array}$ & & & \\
\hline 8 & $\begin{array}{l}\text { [Dns-Pro-Leu-Gly-Leu-Ala- } \\
\text { Gly-(D)Lys-OH].HOAc }\end{array}$ & $889:[M+H]^{\circ}$ & $\begin{array}{l}\text { 6.54: }[M-\text { Dns] } \\
9.51:[M+6.3]^{\circ} \\
970:[M+82] \\
1012:[M+12.3]^{\circ}\end{array}$ & $887:[M-H]$ & 6.54: [M-Dns] \\
\hline 9 & $\begin{array}{l}\text { |Dns-Pro-L_eu-Gly-He-Alat- } \\
\text { Gly-(D)Lys-OH].HOAc }\end{array}$ & 8x9: $|\mathrm{M}+\mathrm{H}|$ & $\begin{array}{l}\text { 95: : }[M+64] \\
1013:[M+124]\end{array}$ & & $\begin{array}{l}\text { 654: [M-Dns] } \\
887:[\mathrm{M}-\mathrm{H}]\end{array}$ \\
\hline 10 & $\begin{array}{l}\text { |H-Nle-Glu-His-(D)Phe-Arg- } \\
\text { Trp-Gly-OCH} \mid .3 \mathrm{HCl}\end{array}$ & $\begin{array}{l}\text { 9.58: } \mid M+H] \\
\text { 986: }|M+28+H|\end{array}$ & $\begin{array}{l}\text { 1(12): }[M+6.3] \\
1049:[M+28+6.3]\end{array}$ & $\begin{array}{l}\text { 956: }[\mathrm{M}-\mathrm{H}] \\
984:[\mathrm{M}+28-\mathrm{H}]\end{array}$ & $97\left(0:[M+13]^{-}\right.$ \\
\hline
\end{tabular}

1). The two neuropeptides substance $P$ and bombesin served as well defined standard materials to provide evidence concerning the capabilities of the method. The eight other samples may have contained traces of formylated and oxidized side-products. Therefore. we could also check the usefulness of the technique for quality control of an organic product. Peptides 3, 4. 5. 6, 7 and 10 were analogues of the melanocytestimulating hormone (MSH) core, whereas peptides 8 and 9 were collagenase enzyme substrates. Four of these peptides $(3,4,6,7)$ had a cyclic structure. two (3. 5) contained a nitro group, whereas two other others $(8,9)$ contained a dansyl group. Several peptides $(3,4$. $7,8,9,10)$ were prepared with the $D$ version of certain amino acids providing the possibility of detecting differences due to symmetry.

Substance $P$ and bombesin were purchased from NovaBiochem (Switzerland). The synthesis of the other cyclic and linear peptides has been described elsewhere." $10^{-4} \mathrm{M}$ solutions of the peptides were prepared using double-distilled water or, in some cases, reagent grade methanol and was mixed with $10^{-2} \mathrm{M}$ nicotinic acid solution in $1: 10$ ratio. About $1 \mu \mathrm{L}$ of this mixture was applied onto an electron-microscope grid coated with Formvar film of about $25 \mathrm{~nm}$ thickness. Both copper and nickel grids were tried and had no influence on the spectra, whatsoever. The sample was dried by a stream of hot air.

\section{RESULTS AND DISCUSSION}

All ten investigated peptides showed favorable response in matrix-assisted laser desorption as compared to the situation without the matrix. In Fig. 1 we demon- strate the typical difference between the laser desorption spectrum of (a) pure peptide 10 (see Table 1) and (b) peptide $\mathbf{1 0}$ in nicotinic acid matrix. There are striking differences between the two spectra. In the case of the pure peptide there is no molecular-ion signal and there are a number of fragment ions present in the low mass range. However, in case (b) a strong molecular ion signal is observed together with adduct ions and ions originating from by-products. It was possible to obtain the matrix-assisted spectrum at much lower irradiance than was used in the case of the pure peptide. Fragmentation of the peptide in this matrixassisted case was not easy to check because of the strong interference from nicotinic acid fragments but in many other cases it became apparent that solitary peptide quasi-molecular ions accompanied by a few nicotinic acid peaks and with no ions due to peptide fragmentation can be achieved.

Negative-ion spectra of all the samples were also taken. Strong quasimolecular peaks are much less common than they are in the positive-ion mode. However, as one can conclude from Table 1 weaker peaks might be characteristic. In Fig. 2 the positive-ion (a) and negative-ion (b) spectra of peptide 8 are compared. In the positive-ion mode the peak due to the protonated molecule has severral satellite peaks. Among them is the adduct of the peptide with a matrix molecule: $[\mathrm{M}+123]^{+}$. This type of peak has previously been observed in reflection geometry experiments. "2 Their presence was suggested as the cause of intensive peak broadening in the very high mass region, where the mass resolution of the time-of-flight analysers is insufficient to separate them from the molecular-ion 

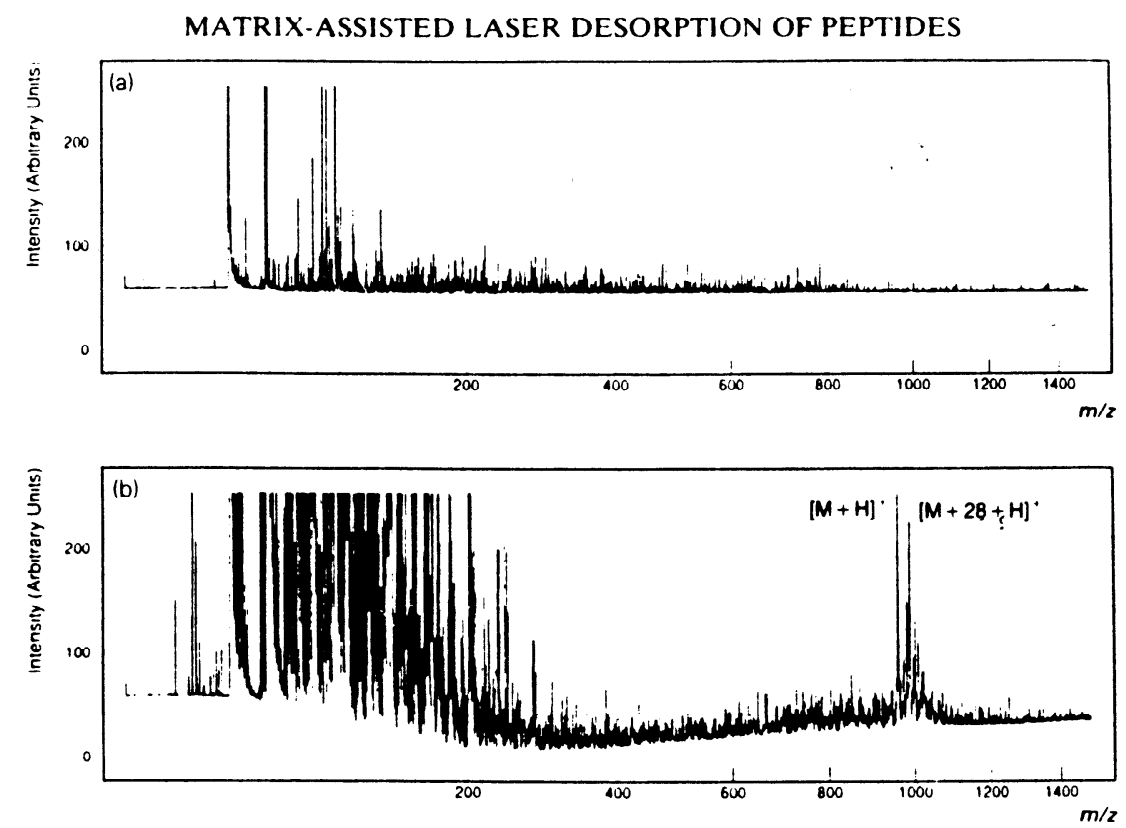

Figure 1. Single shot laser desorption spectra of peptide 8 in transmission geometry: (a) without and (h) with matrix assistance. No peptide-specific ions are observed without matrix. The matrix assisted method shows dramatic enhancement of the molecular ion signal even in the absence of substrate.

peak. The negative-ion spectrum in Fig. 2(b) shows no significant satellite peak formation.

Further inspection of the ion abundances in Table 1 leads to several conclusions. (i) Both substance $P$ and bombesin showed strong positive-ion ion signals due to protonated molecules. Bombesin is known not to give stable molecular ion signals in the widely-used fastatom bombardment method because of its hydrophilic character. On the other hand no problem arises in acquiring the laser-desorption spectra. (ii) In the case of synthesized products it is possible to observe minor $(3,4,5)$ and major $(3,10)$ by-products with oxidized and with formylated moieties. (iii) Either the loss of the nitro group or the presence of a by-product without the nitro group can be confirmed from the spectra of samples 3 and 5. Dansyl derivatives may show loss of the dansyl group in part (8). (iv) Cyclic and linear peptides show no characteristic differences in ion formation. (v) No significant distinction according to optical activity was evident. (vi) In quite a number of cases an adduct ion appears at either $[M+62]^{+}$, $[M+63]^{+}$or $[M+64]^{+}(6,7,8,9,10$ and sometimes 1 and 2). We have found no clear explanation for this phenomenon. One obvious answer is to attribute these peaks to some kind of contamination. Their occasional appearance in the spectra of the commercial neuropeptides, however, makes this explanation unsatisfactory. Another possibility is to correlate these peaks with the presence of a doubly charged cluster adduct: $[2 \mathrm{M}+\text { nicotinic acid }]^{2+}$. It is difficult to understand, however, why and how this structure should arise, bearing in mind the numerous other possible clusters that could be envisaged but which did not show up in the spectra.

We find it instructive to check the detection limit achieved in this experiment. Assuming that a $3 \times$ $10^{-11} \mathrm{~cm}^{-3}$ volume element of the matrix is evaporated. one arrives at a rough estimate of $\sim 3 \times 10^{-13}$ mole
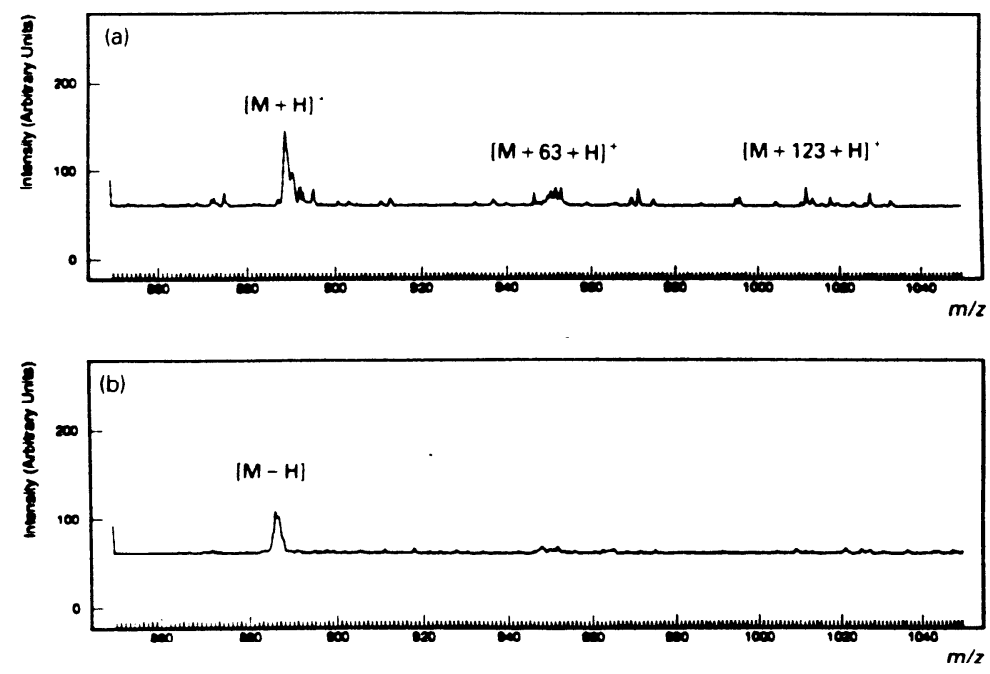
matrix and about $10^{-15}$ mole analyte consumption in a single laser shot. This femtomole detection limit provides unique capabilities for this method. In the case of neutropeptides this means that about a picogram of the analyte is identifiable.

It is appropriate to comment on the present findings in relation to our suggested mechanism of matrixassisted laser desorption. ${ }^{13.14}$ Our homogeneous bottleneck model describes the volatilization process as an electronic excitation of the matrix by the UV laser pulse, followed by internal conversion to its vibrational excitation and a competition between energy transfer to the lattice vibrations and to the guest or analyte molecules. This latter is blocked by an energy transfer bottleneck caused by the frequency mismatch between the matrix chemical bonds and the matrix-guest hydrogen bonds and by the scarcity of guest molecules. An important feature of this model is that it does not consider substrate participation, a mechanism which it was not possible to exclude on the basis of reflection type experiments. The measurements presented here support the idea of a homogeneous mechanism at least in the mass range investigated in this communication.

\section{Acknowledgement}

The authors are grateful $10 \mathrm{~K}$. Medzihradszky and to J. Boidi at the Organic Chemistry Department of the Eotvos Lorind University. Budapest. for kindly providing the ssinthesized peptide samples and to M. Clacys at the Pharmaceutical Department of The University of Antwerp (UIA) for stimulating and encouraging discussions.

\section{REFERENCES}

1. M. Karas, D. Bachmann. U. Bahr and F. Hillenkamp, Int. J. Mass Spectrom. Ion Proc. 78. 53 (1987).

2. Papers presented at the 2nd International Symposium on Applied Mass Spectrometry in the Health Sciences. April 1990. Barcelona. Spain. Concerning procecdings contact E. Gelpi, Barcelona. Spain

3. Papers presented at the Proceedings of the 38th Annual Conference on Mass Spectrometry and Allied Topics. Tucson. AZ. ASMS. East Lansing (to be published. 199(1)).

4. Papers presented at the NATO Advanced Research Workshop on the Methods and Mechanisms for Producing lons from Large Molecules. June 1990. Minaki. Ontario. Canada. To be published as a volume in the NATO ASI Science Series. Plenum Press.

5. B. Sundqvist, R. D. Macfarlane. Mass Spectrom. Rev. 4, 421 (1985).

6. J. B. Fenn. M. Mann. C. K. Meng. S. F. Wong. C. M. Whitehouse, Mass Spectrom. Rev. 9. 37 (199()).

7. M. Karas. U. Bahr. A. Ingendoh and F. Hillenkamp, Angen: Chem. Int. Ed., Engl. 28. 76) (1989).

8. B. Spengler. J. Dolce, Y. Pan and R. J. Cotter in Ref. 2; M. Karas, U. Bahr. A. Ingendoh. B. Stahl, K. Strapat, E Nordoff and F. Hillenkamp in Ref. 2.

9. R. C. Beavis and B. T. Chait. Rapid Commun. Mass Spectom. 3. 432 (1989).

10. R. C. Beavis and B. T. Chait. Rapid Commun. Mass Spectrom. 3. $436(19 \times 9)$

11. H. Medzihradszky-Schweiger, H. Süli-Vargha. J. Bódi and K. Medzihradszky. Collect. Czechoslovak Chem. Commun. 53. $257+(1988)$.

12. R. C. Beavis and B. T. Chait. Rapid Commun. Mass Spectrom. 3. $233(1989)$

13. A. Vertes. R. Gijhels and R. D. Levine, Rapid Commun. Mass Spectrom. 4, $22 \times(199)$ )

14. A. Vertes and R. D. Levine. Chem. Phys. (in press).

Received 30 May 1990): accepted I June 1990. 